\title{
Editorial
}

\section{Unexpected Low Covid 19 Mortalities Across Africa: What Could have Happened?}

\author{
Onoja MA, ${ }^{1}$ Oloche JJ, ${ }^{2}$ Jombo GTA, ${ }^{3}$ Onoja TA. ${ }^{4}$ \\ ${ }^{\prime}$ Department of Haematology and Blood transfusion, College of \\ Health Sciences, Benue State University, Makurdi, Nigeria. \\ ${ }^{2}$ Department of Pharmacology and Therapeutics, College of \\ Health Sciences, Benue State University, Makurdi, Nigeria. \\ ${ }^{3}$ Department of Medical Microbiology and Parasitology, \\ College of Health Sciences, Benue State University. \\ ${ }^{4}$ Department of Medical Microbiology, University of \\ Agriculture, Makurdi, Nigeria.
}

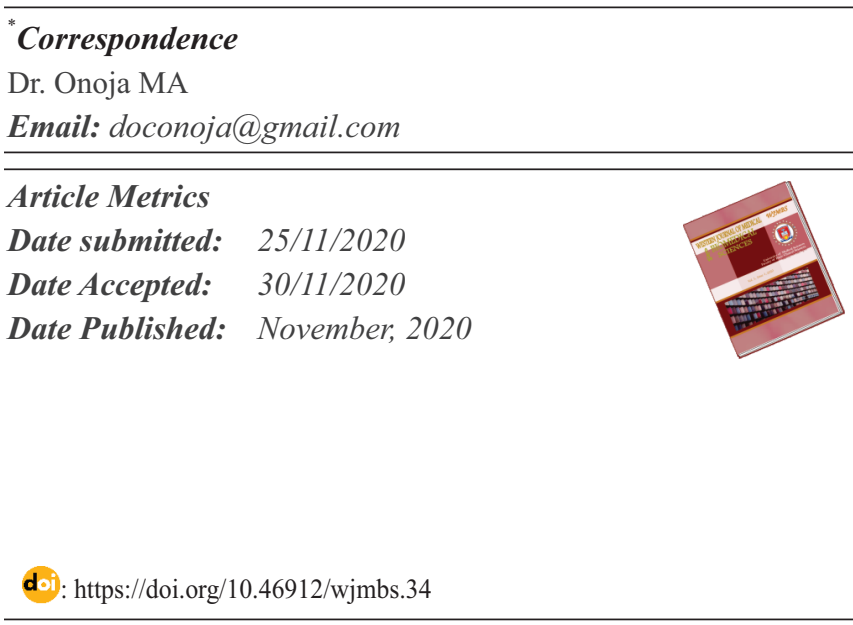

\section{ABSTRACT}

COVID-19 mortalities have continued to be surprisingly low across Africa against all the earlier predictions. This has baffled the global scientific community and several hypotheses and theories have been propounded to explain the underlying factors for this unexpected occurrence. We found out that none of the theories is free of technical flaw, no matter how as plausible as it may appear it does not fully explain this phenomenon. Hence, we conclude that the mystery behind COVID-19 on African soil is yet to be unraveled. Meanwhile preventive measures already on ground should be sustained to keep the disease permanently low.

Keywords: Africa, COVID-19, Mortalities, Unexpected

\section{BACKGROUND}

When the outbreak of COVID-19 was officially announced in China late December 2019, ${ }^{1}$ the Chinese health authorities went into aggressive measures to contain the spread of the disease in Wuhan, and other parts of China. Despite the heroic approach by the government of China the disease did still caused massive casualties before it was brought under control. While the fight to eradicate the disease was ongoing, inter border transmission to Europe and America and other parts of
Asia such as Thailand ${ }^{2}$ had started.

Global records of COVID-19 at $3{ }^{\text {rd }}$ December 2020, shows that the total COVID-19 infections stood at $65,750,270$ cases with 1, 515, 748 deaths while 45, 574,663 have so far recovered. USA has the highest casualties with $14,551,416$ cases and 283,072 deaths, followed by Brazil with 6, 487,516 cases and 175,307 deaths to be followed by India with $9,590,086$ cases with 139,433 deaths. Africa with a population of 1.4 Billion people representing $16.72 \%$ of total world population of 7.8 Billion so far has recorded $2,215,216$ cases with 52,824 deaths; this translate to $3.5 \%$ 
of total global deaths. ${ }^{3}$

When the disease started wrecking havoc in countries with well established healthcare facilities and standard of care much better than Africa and the disease was heading towards Africa; there was generally mind bugling predictions about the amount of catastrophe the disease would cause when it finally arrives. These predictions of doom for Africa using various epidemiological statistical models were not out of place considering the poor health facilities, low funded health budgets, overcrowded and clustering communities, widespread social unrests with mass displacements, and a continent still struggling with several other infectious diseases among others. In fact some cities in Africa were predicted to be literally wiped out. ${ }^{4}$

Six, Seven, Eight, Nine months into the pandemic and still counting, the situation in Africa appear not to have generally changed as the rate of infections and deaths have still remained surprisingly low. This development remains a puzzle for scientists and researchers across the globe to which several theories have been propounded as the likely cause or causes of this strange occurrence.

a. Age structure. The average age population demography of African countries is such that age $\geq 65$ accounts for $3 \%$, while a predominant $60 \%$ represents age $<25$ of the total population. The population distribution in Africa favours the youthful age that appears to be less susceptible to death from COVID-19 compared to $18 \%$ of population age $>60$ of Europe and north America where the disease caused most deaths. An adjustment of the age-related deaths from COVID-19 involving Western Europe and Africa has been done and yet many deaths in Europe could not be adequately explained by this theory. ${ }^{5}$

b. Inadequate testing facilities and lack of proper documentation. It was hypothesized that the inadequate or lack of testing for COVID-19 across Africa culminates to gross under reporting of the disease and deaths from the disease. This might somewhat contribute to the low figures emanating from Africa. This hypothesis was not supported because there are no unusual large scale sudden deaths involving African cities sufficiently different from the normal patterns of deaths been recorded in the past, during this period of COVID19 pandemic. $^{5}$

c. Atmospheric Temperature and Humidity. The general climate in Africa is humid and warm and this makes the respiratory tract to fight Coronavirus more efficiently and eliminates it leading to less deaths. One fact that challenges this hypothesis is that not all African countries have similar humid tropical climate, and where it exists, it is rather seasonal. ${ }^{6}$

d. BCG vaccination. Bacillus Calmette-Guerin is vaccine given to children shortly or $<6$ months after birth for prevention against pulmonary tuberculosis and is usually given in most African countries. It has been postulated that this vaccine may confer protection against COVID-19 and may have contributed to the low COVID-19 mortalities across Africa. More research may be required to establish this proposition. ${ }^{6}$

e. Infectious disease burden in Africa. Africa is known for infectious disease burden involving bacteria, parasites, fungi and viruses. It was inferred that the heavy disease burden among Africans may have equipped them better to fight newer infections from cross immunity. This concept has largely remained unproven and the conferment of heterologous immunity against unrelated pathogens is very low due to high specificity and species conserved nature of microbial antigens. However, a prior infection with structurally related SARS-Cov 1 and MERSCov could produce cross-reacting antibodies against newer Corona viruses such as SARS-Cov 2. ${ }^{7}$ These Coronaviruses have not been known to produce a large-scale infection across Africa in the past so as to confer on Africans the present COVID-19 benefits.

f. Genetic disposition. Differences in genetic composition among Europeans, Asians and Africans have also being propounded as a 
possible explanation. A group of genes associated with increased risk of severity to infections have been found among Asians and Europeans but absent among Africans. To substantiate this school of thought, ${ }^{8}$ it would be important to establish the availability of these genes among black and white American population.

g. Population Density. Findings have shown that population density in Africa is generally low compared to countries like United Kingdom, Italy with 275 and 208 per sq kilometer respectively compared to most African countries with population densities of $\leq 50$ per sq kilometer. The population density of 36 per sq kilometer in USA with high death toll tends to weaken this proposition. It is also a fact that cities like Lagos and Abuja have population densities probably more than Italy and U K combined, ${ }^{7}$ yet infection and death rates due to COVID-19 infection is very low compared to those of Italy and UK.

h. Less travel among Africans. Compared to the well developed countries, African nationals generally travel far less, therefore the tendency to move and contract disease frequently is drastically low. It is on record that on the entire landscape of Africa it is only OR Thambo International airport Johannesburg that is ranked among the very busy international airports of the world.' The fact that COVID-19 took a longer time to reach African continent and the disease had its foothold in South Africa further gives credence to this belief. ${ }^{9}$ Some of the earlier infections recorded in New York city were however strangely among those who had no recent international travel history nor high risk positive exposures.

i. Experience with Epidemics. Africa has had contact with several epidemics in the past; including Lassa fever, Ebola, and Yellow fever. They have therefore developed over time a measurable wealth of experience to combat any new epidemic that emerges better than the western world with no prior experience. For this reason,
Africans appear to be better prepared to deal with these outbreaks which have built their capacity to contain COVID-19 much better. A classical example is the simple wearing of face masks which had much more better compliance among Kenyans and Nigerians than British and Italians. These countries also responded more swiftly by closing their borders and implementing hand washing and social distancing.

j. Herd immunity theory. This hypothesis states that endemic poverty and the overcrowding in Africa leads to high transmission of infection resulting to herd immunity and resist any newer infections. This explains the high rates of COVID-19 infections in Italy, UK, France and USA, but not the low infection rate in Africa. The high rate of infection and mortality in Brazil that has similar environmental and social factors with several African countries, is not in favour of this postulation. ${ }^{11-13}$

k. Protection of Africans within malaria endemic areas. Plasmodium falciparum malaria is endemic in sub-saharan African regions that extends from Senegal and Gambia in west Africa through Cameroun in central Africa to Kenya and Ethiopia in the east down to DR Congo, Botswana and Gabon to the south. Outside Africa, malaria malaria is endemic in central and south America in the west to South-east Asia (Cambodia, Thailand, Vietnam, China, India, Bangladesh) to the east. There is apparent immune-dominant epitope conservation between SARS-COV-2 and $P$. falciparum thrombospondin-anonymous-related protein preventing such malaria patients from contracting COVID-19. The high COVID-19 mortalities recorded in Brazil and India, two countries with high malaria burden roundly overthrows this assertion. ${ }^{14}$

\section{Conclusion}

While one single death from COVID-19 is very significant, the death rate from African continent 
from the disease is comparatively low. Although some of the explanations given appear convincing, none is completely exempt from a serious technical flaw. This leaves us with the conviction that it may take some time before the scientific world will unravel what happened or may have happened to Africa concerning COVID-19. Meanwhile the control measures of wearing face masks, social distancing, regular hand washing and no hand shake should be sustained on the continent.

\section{REFERENCES}

1. Onoja AM, Jombo GTA, Onoja AT, Nwannadi AI, Aba IH. Extrapulmonary Manifestations of COVID-19: A Call to Extra Vigilance and Tribute to Dr Li Wenliang. Western J Med and Biomed Sci [internet], 2020jun. 16 [cited 2020Dec.8];1(1):xi-xiv. Available from: https://wjmbs.com.ng/index.php/wjmbs/article/view/5 .https://doi.org/10.46912/wjmbs.5

2. Zhu H, Wei L, Niu P. The novel coronavirus outbreak in Wuhan, China. Glob Health Res Policy. 2020; 5: 6e. https://doi.org/10.1186/s41256-020-00135-6.

3. Worldometer. Coronavirus report. https://www.worldometers.info/coronavirus/?utm ca mpaign=homeAdvegas1?. Accessed $4^{\text {th }}$ December, 2020.

4. Nkengasong J, Mankuola W. Looming threat of COVID-19 infection in Africa: act collectively, and fast. The Lancet 2020; 395(10227)e.

5. Zhao Z, Li X, Liu F, Zhu G, Ma C, Wang L. Prediction of the COVID-19 spread in African countries and implications for prevention and control: a case study in South Africa, Algeria, Nigeria and Kenya. Sci of The Total Environ. 2020;729e.

6. Njenga MK. Dawa J, Nanyingi M, Gachohi J, Ngere I, Letko $\mathrm{M}$, et al. Why is there low morbidity and mortality of COVID-19 in Africa? The Am J Trop Med \& Hyg. 2020; 103(2)e.

7. Health and Medicine. Why Africa has seen such low
d e a t h
$r$ a $\mathrm{t}$ e $\mathrm{s}$.

https://www.pri.org/stories/2020-10-14/why-africahas-seen-such-low-covid-19-death-rates.

8. Science. Genes that sway the course of Coronavirus $\begin{array}{lllll}f & 0 & u & n & d\end{array}$ https://www.sciencemag.org/news/2020/10/foundgenes-sway-course-coronavirus.

9. Mehtar S, Preiser W, Lakhe NA, Bousso A, Tamfum JM. Limiting the spread of COVID-19 in Africa: one size mitigation strategies do not fit all countries. The Lancet Global Health. 2020; 8(7): E881-E883.

10. Evening Standard. Scientists suggest new theory over Africa's low Covid-19 death rate. https://www.standard.co.uk/news/world/africa-lowcoronavirus-levels-a4539286.html.

11. Science. The pandemic appears to have spared Africa so far. Scientists are struggling to explain why. https://www.sciencemag.org/news/2020/08/pandemicappears-have-spared-africa-so-far-scientists-arestruggling-explain-why.

12. Aiyewumi O, Okeke MI. The myth that Nigerians are immune to SARS-CoV-2 and that COVID-19 is a hoax are putting lives at risk. J Glob Health. 2020;10(2):020375. doi:10.7189/jogh.10.020375.

13. Cambaza EM, Viegas GC, Cambaza CM. Potential impact of temperature and atmospheric pressure on the number of cases of COVID-19 in Mozambique, Southern Africa. J of Public Health \& Epidemiol. 2020; 12(3), 246-260.

14. Iesa MA, Osman ME, Hassan MA, Dirar AI, Abuzeid N, Mancuso JJ, et al. SARS-COV2 and P. falciparum common immunodominant regions may explain low COVID-19 incidence in the malaria-endemic belt. New Microbes and New Infections. 2020 ; https://doi.org/10.1016/j.nmni.2020.100817. 